\title{
Effects of Extract and Phenol Glycoside from Rose Petals on the Amylin Fibrils
}

\author{
Karlen Hovnanyan'1, Svetlana Sharoyan², Alvard Antonyan², Narek Hovnanyan', \\ Sona Mardanyan ${ }^{2}$
}

\author{
${ }^{1}$ Institute of Molecular Biology of Armenian National Academy of Sciences, Yerevan, Armenia \\ ${ }^{2}$ Institute of Biochemistry of Armenian National Academy of Sciences, Yerevan, Armenia \\ Email: hovkarl@mail.ru,biochem@ipia.sci.am
}

How to cite this paper: Hovnanyan, K., Sharoyan, S., Antonyan, A., Hovnanyan, N. and Mardanyan, S. (2017) Effects of Extract and Phenol Glycoside from Rose Petals on the Amylin Fibrils. Open Access Library Journal, 4: e3343.

http://dx.doi.org/10.4236/oalib.1103343

Received: December 30, 2016

Accepted: January 17, 2017

Published: January 20, 2017

Copyright $\odot 2017$ by authors and Open Access Library Inc.

This work is licensed under the Creative Commons Attribution International License (CC BY 4.0).

http://creativecommons.org/licenses/by/4.0/

\section{(c) (7) Open Access}

\begin{abstract}
Peptide amyloidoses are considered as causes of a variety of pathologies (Alzheimer's disease, Parkinson's disease, type 2 diabetes, etc.). In the present work, the results of the transmission and scanning electron microscopy (TEM and SEM) were used to study the effects of the ethanol extract of rose petals and phenol glycoside fraction, isolated from it, on the fibrillation of the amyloid polypeptide amylin (AIAPP), which is toxic for islet cells. At TEM and SEM visualization of amylin fibrils, the size, form-factor, distribution by dimension and by polymorphism degree were taken into account. The nature of conformational diversity of aggregates of varying degree was analyzed. The analyses showed simultaneous presence of various structural forms: protofibrils, mature fibrils and ribbon-like forms. In case of plant preparations, a) inclusions of their particles caused increase of fibril dimention; b) amorphous bundles without clear configuration of the structure appeared, etc. These observations are in concordance with the earlier observed ability of these plant preparations to hinder the amylin fibrillation and to protect the islet cells from the toxicity of aggregated amylin. The findings of the present work demonstrate TEM and SEM as reasonable approaches in seeking effective antiamyloidogenic agents.
\end{abstract}

\section{Subject Areas}

Biochemistry

\section{Keywords}

Electron Microscopy, Amylin, Amyloidosis, Ethanol Extract of Rose Petals, Phenol Glycoside from Rose Petals 


\section{Introduction}

Misfolding of proteins and peptides leads to the formation of strictly ordered amyloid aggregates [1] [2]. Amyloid fibrils are similar in morphology and structure, regardless of the amino acid composition and sequence of the forming peptides [3] [4]. The amyloid state of a peptide is more stable thermodynamically, and its native state is the metastable state [5]. Peptide amyloidosis is considered as a cause of a variety of pathologies [6]. Misfolding of peptides, self-assembly into insoluble amyloid fibrillar structure, and formation of strictly ordered accumulations underlie many amyloid-related diseases (the amyloid proteins are indicated in brackets): Alzheimer's disease (amyloid $\beta$-peptides, tau protein); Parkinson's disease ( $\alpha$-synuclein); type 2 diabetes (amylin); dialysis amyloidosis ( $\beta 2$-microglobulin); cataract (crystallin); lysozyme-systemic amyloidosis (lysozyme); etc. [6] [7] [8] [9].

Currently, there are no approved therapeutic agents against formation of fibrillar assemblies. The high cost and side effects of synthetic drugs, as well as non-complete recovery of patients due to their usage, induced researches on the development of approaches based on the use of natural products. Natural compounds with a broad spectrum of biological activities are considered as agents reducing the risk of many diseases [10] [11] [12] [13] [14], and can serve as sources for the development of new therapeutic drugs [15].

Amylin, a 37 amino acid containing amyloid polypeptide, is a major secretory product of pancreatic $\beta$-cells [16] [17]. It is a regulatory peptide inhibiting the secretion of glucagon and insulin in the islet $\beta$-cells and functioning in some distant organs also (for instance, in brain). Amyloid deposits of amylin were found in the islet $\beta$-cells in type 2 diabetes (T2D) in humans. The aggregated amylin plays a significant role in the loss of $\beta$-cells in T2D and in pancreatic islets transplanted into individuals with T1D [18].

It had been shown that such natural plant compounds as flavonoids (myricetin, quercetin, kaempferol, etc.), polyphenols (rosmarinic acid, curcumin, etc.) [19] [20] [21] are capable of inhibiting the amyloidosis of amylin. Epigallocatechingallate, a polyphenol from green tea, inhibited the in vitro amyloidogenesis of amylin and destabilized its preformed aggregates [22]. Obviously, the cytotoxicity of amylin against $\beta$-cells can be reduced by the plant preparations, possessing such properties.

Earlier, using the transmission electron microscopy, fluorescent microscopy and Thioflavin-T staining, we demonstrated in vitro the ability of the purified bovine kidney dipeptidyl peptidase IV to hinder the aggregation/fibrillation of $\mathrm{A} \beta(1-40)$ and $\mathrm{A} \beta(1-42)$ peptides and to disaggregate their preformed fibrils [23].

Recently we have shown the in vitro protection of islet $\beta$-cells against toxicity of aggregated amylin by ethanol extracts of rose petals (Rosa damascena) and several other plants, as well as by eleven fractions isolated from them, including phenol glycosides [24]. For some of the studied plant preparations, $\mathrm{IC}_{50}$ values in protecting $\beta$-cells were significantly low. The amelioration of amylin aggregation state by these preparations was manifested using ThT fluorescence method. This 
finding was in strong correlation with the protection of $\beta$-cells. Then the reverse of preformed amylin aggregates in the presence of several plant preparations was shown, and the promotion of viability of $\beta$-cells has been registered with DNAcomet analysis and trypan blue exclusion test [25].

The present work studies (with the use of transmission and scanning electron microscopies) the effects of ethanol extract from rose petals, and the isolated from it phenol glycoside fraction on amylin fibrils.

\section{Materials and Methods}

\subsection{General}

Thioflavin T (ThT) was purchased from Sigma Ltd, USA; G-25 and LH-20 Sephadex-from Pharmacia Biotech, Uppsala, Sweden, and amylin-from "GeneCust" (Luxembourg). All the other chemicals were of the highest purity.

Spectral measurements were performed on spectrophotometer Specord M-40 UV-VIS (Germany) and spectrofluorometer Perkin-Elmer MPF-44A (USA), using quartz cuvettes with light path 0.5 and $1 \mathrm{~cm}$ at $25^{\circ} \mathrm{C}$ in thermostatic cuvette holders.

\subsection{Preparation of Specimens for Electron Microscopy}

On the copper grids coated with formvar the suspension of the preparate was applied dropwise, in 1 minute the liquid was removed and the specimens were negatively stained with $1.0 \%$ phosphorous tungsten solution, $\mathrm{pH} 7.2$ or with $2 \%$ aqueous uranyl acetate. They were registered in the transmission electron microscope (TEM) JEM-1400PLUS TUNGSTEN, operating at accelerating voltage of $80 \mathrm{kV}$, and in the scanning electron microscope (SEM) JSM-5410 of the company JEOL, operating at accelerating voltage from 0.5 to $30 \mathrm{kV}$. Both the microscopes were provided with the image recording digital system.

\subsection{Plant Material}

The rose petals (Rosa damascena) purchased from Phytotherapeutic Center "Artemisia" (Armenia) were dried in the shade. The dried material was grinded and $10 \%(\mathrm{w} / \mathrm{v})$ extract was prepared in $70 \%(\mathrm{v} / \mathrm{v})$ ethanol $(72$ hours at ambient temperature). The extract was filtered through a sterile cheese cloth, dried by evaporation at $37^{\circ} \mathrm{C}$ and stored at $-18^{\circ} \mathrm{C}$ until using [26].

To obtain the fractions, 1 - $3 \mathrm{mg}$ of the extract was dissolved in $2 \mathrm{ml}$ of $70 \%$ ethanol and subjected to sequential gel filtrations on LH-20 and G-25 Sephadex columns, as described earlier [26] [24]. The constituents of the extract and the isolated fractions were characterized by optical absorbance in UV-Vis region, identified by qualitative chemical analysis and thin layer chromatography [26].

\subsection{Peptide Preparation}

To prepare stock solution of amylin, $0.8 \mathrm{ml}$ of bidistilled water was added to 1 $\mathrm{mg}$ peptide, and centrifuged $(5000 \mathrm{~g} \times 10 \mathrm{~min})$ after standing for $30 \mathrm{~min}$. The absorption spectrum of the supernatant was recorded in the range $230-320 \mathrm{~nm}$. 
The molar concentration of the peptide was evaluated using the molar extinction coefficient of tyrosine at $276 \mathrm{~nm}, 1.39 \mathrm{mM}^{-1} \cdot \mathrm{cm}^{-1}$. The fibrils of amylin were formed at incubating for 7 days at $37^{\circ} \mathrm{C}$ the protein at concentration of $125 \mu \mathrm{M}$ in $20 \mathrm{mM}$ HEPES buffer, $\mathrm{pH} 7.2$, containing $0.02 \% \mathrm{Na}$ azide (w/v). The fibrilization state of peptide was evaluated by ThT staining as described elsewhere [23] [27] and measuring the fluorescence intensity at $\lambda_{e x}=430 \mathrm{~nm}$ and $\lambda_{e m}=485 \mathrm{~nm}$. To evaluate the effects on the amylin fibrilation of the ethanol extracts of rose petals and the isolated from it phenol glycoside fraction, the identical solutions of the peptide were incubated in their absence and presence, in the conditions, noted above.

\section{Results}

At electron-microscopic visualization and identification of amylin fibrils, the size, form-factor, distribution by dimension and by polymorphism degree were accounted. The nature of the accumulation of fibrils as separate particles or as aggregations of varying degrees was assessed.

The TEM images of the suspension of $125 \mu \mathrm{M}$ amylin in $20 \mathrm{mM}$ HEPES buffer, $\mathrm{pH} 7.2$, incubated for 7 days at $37^{\circ} \mathrm{C}$ are shown in Figure 1. Preliminarily, the fibrillation of the peptide was manifested by ThT staining and measuring the fluorescence intensity (see Materials and Methods). Figure 1 shows polymorphism of amylin fibrillation, expressed both in the length of the fibrils (from $100 \mathrm{~nm}$ to $31.4 \mu \mathrm{m}$ ), and in the diameter (from $7 \mathrm{~nm}$ to $100 \mathrm{~nm}$ ). Besides, the presence of different forms of oligomerization, specifically, of protofibrils (Figure 1(a)) and mature fibrils (Figure 1(b)), also suggest polymorphism. In the aggregated fibrils, the transformation into ribbon-like formations with the diameter in the 20 - $60 \mathrm{~nm}$ range (Figure 1(c)) is observed. Figure 1(d) demonstrates that ribbon-like formations are observed concurrently with aggregated fibrils.

As we noted in the Introduction, the amelioration of amylin fibrillation state by the ethanol extracts from rose petals (Rosa damascena) and several other plants, as well as by isolated eleven fractions (phenol glycosides among them) was shown earlier [24]. Therefore, we compared the above described properties of amylin fibrils with those, formed during the peptide incubation in the presence of $0.02 \%$ ethanol extract of rose petals and phenol glycoside fraction from this extract. Their SEM images are shown in Figure 2 and Figure 3, respectively.

The analysis with SEM technique evidenced increased polymorphism of fibrils at incubation of amylin in the presence of the ethanol extract from rose petals or phenol glycoside fraction isolated from it. In the presence of the extract (Figure 2), the diameter of the fibrils increased up to $50-60 \mathrm{~nm}$ (Figure 2, arrow 1) and the longitudinal breakthrough appeared (Figure 2, arrow 2). The formed clearances were occupied with extract particles with dimensions up to $8 \mathrm{~nm}$ (Figure 2 , arrow 3 ).

This pattern is similar to that for amylin fibrils interacting with enzyme catalase, described in the literature [28].

The effects of the used plant preparations vary by the degree of fibrillation: the 
fibrillation extent for the phenol glycoside fraction is more pronounced than that for the extract. In Figure 3(a), the increased diameter of fibril is shown by arrow 1, the longitudinal breakthrough of the fibrils are shown by arrows 2 . Un-

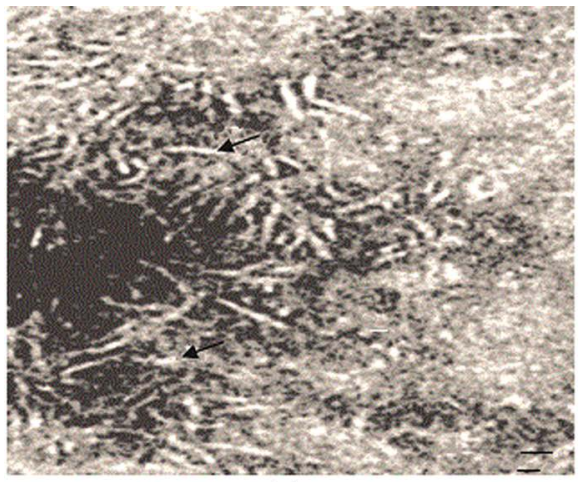

(a)

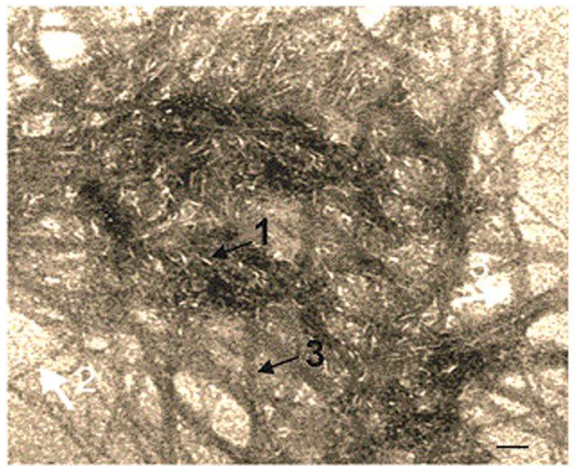

(c)

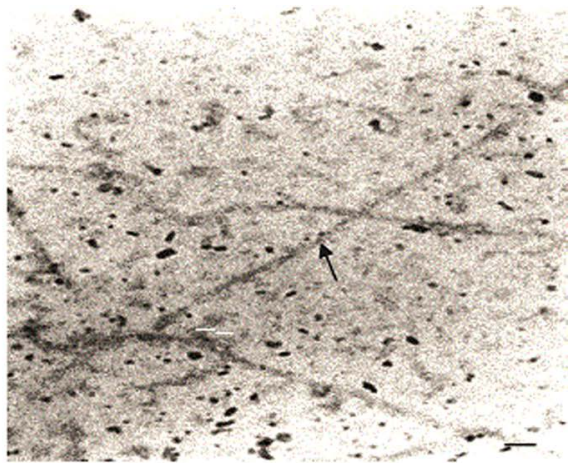

(b)

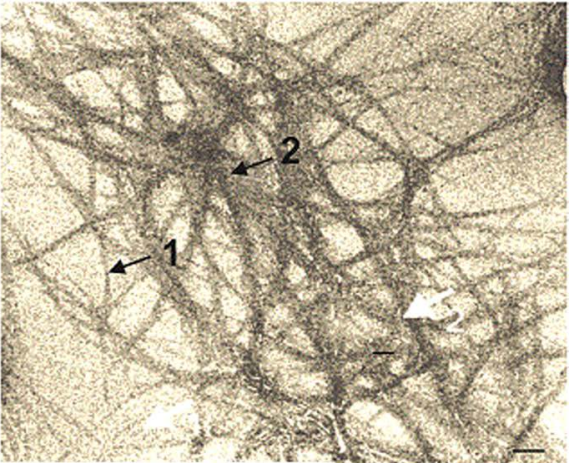

(d)

Figure 1. The TEM images of the suspension of amylin, aggregated for 7 days incubation in $20 \mathrm{mM}$ HEPES buffer, $\mathrm{pH} 7.2$, at $37^{\circ} \mathrm{C}$. (a) protofibril forms; (b) mature fibrils (shown by arrows); (c) the protofibrils are indicated by arrow 1 , mature form fibrils transformed into ribbon-like formations-by arrow 3; (d) the mature fibrils are indicated by arrow 1 , the ribbon-like formations-by arrow 2 . Scale bars: $100 \mathrm{~nm}$.

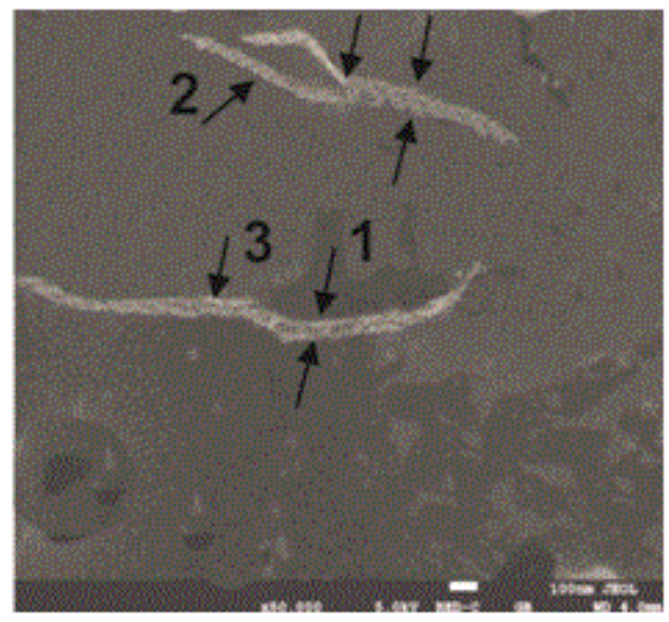

Figure 2. The SEM picture of the suspension of amylin, aggregated in the presence of $0.02 \%$ ethanol extract of rose petals (the conditions as in the Legend of Figure 1): arrow 1 indicates the increased in diameter fibrils, arrow 2-the longitudinal breakthrough forms of fibrils, arrow 3-the particles of the extract, included into fibrils. Scale bar: $100 \mathrm{~nm}$. 


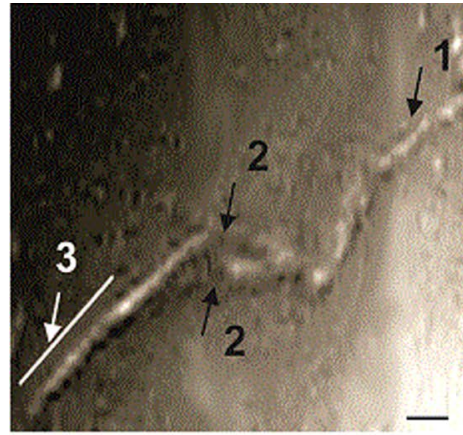

(a)

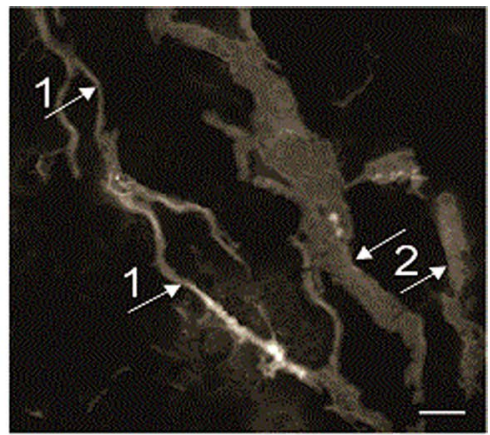

(b)

Figure 3. The SEM pictures of the suspension of amylin, aggregated in the presence of $0.02 \%$ of phenol glycoside fraction from the ethanol extract of rose petals (the conditions as in the Legend of Figure 1). (a) arrow 1 indicates the amylin fibrils with the diameter of $50-60 \mathrm{~nm}$, arrows 2-the longitudinal breakthrough forms of the fibrils, arrow 3-the spiralized part of the fibrils; (b) the amorphous bundles of fibrils without clear configuration are seen. Scale bars: $100 \mathrm{~nm}$.

der the impact of phenol glycoside, spiralization of amylin fibrils was also observed (Figure 3(a), arrow 3). In this case, concurrently with the fibrillar structures, the amorphous bundles of fibrils without clear configuration were observed (Figure 3(b)).

\section{Discussion}

The transmission and scanning electron microscopy analysis of conformational changes at amylin oligomerization manifested simultaneous presence of various structural forms: protofibrils, mature fibrils and their ribbon-like formations. In case of amylin incubation in the presence of plant preparations, the inclusion of their components increased the fibril dimensions. In addition to the fibril structures, the amorphous bundles are observed without clear configuration of their structure.

These observations can be considered as manifestation of the loosening of the fibril structure in the presence of the ethanol extract and phenol glycoside fraction, which can induce the decomposition of fibrils. Indeed, in our previous researches significantly low $\mathrm{IC}_{50}$ values have been estimated for the extract and phenol glycoside from rose petals $(1.45 \pm 0.26$ and $0.15 \pm 0.05 \mu \mathrm{g} / \mathrm{ml}$, respectively) in protecting islet beta cells from killing by fibriled amylin [24]. These parameters were in strong correlation with the ability of the preparations to inhibit the peptide fibrillation and disaggregate its preformed fibrils [25].

The presented observations confirm the TEM and SEM analyses as reasonable approaches to the evaluation of the effectiveness at search of anti-amyloidogenic agents.

\section{Acknowledgements}

This work was supported by the RA MES State Committee of Science, in the frames of the research project № 13-1F186.We thank the late manager-director Benjamin Bammes for support electron microscopic operations. 


\section{Conflict of Interests}

The authors declare no conflict of interests with respect to the present paper.

\section{References}

[1] Zerovnik, E. (2002) Amyloid Fibril Formation. Proposed Mechanisms and relevance to Conformational Disease. European Journal of Biochemistry, 269, 3362 3371. https://doi.org/10.1046/j.1432-1033.2002.03024.x

[2] Greenwald, J. and Riek, R. (2010) Biology of Amyloid: Structure, Function, and Regulation. Structure, 18, 1244-1260. https://doi.org/10.1016/j.str.2010.08.009

[3] Chiti, F. and Dobson, C.M. (2006) Protein Misfolding, Functional Amyloid, and Human Disease. Annual Review of Biochemistry, 75, 333-366. https://doi.org/10.1146/annurev.biochem.75.101304.123901

[4] Chiti, F. and Dobson, C.M. (2009) Amyloid Formation by Globular Proteins under Native Conditions. Nature Chemical Biology, 5, 15-22. https://doi.org/10.1038/nchembio.131

[5] Baldwin, A.J., Knowles, T.P.J., Tartaglia, G.G., Fizpatrick, A.W,, Devlin, G.L., Shammas, S.L., Waudby, C.A., et al. (2011) Metastability of Native Proteins and the Phenomenon of Amyloid Formation. Journal of the American Chemical Society, 133, 14160-14163. https://doi.org/10.1021/ja2017703

[6] Sipe, J.D., Benson, M.D., Buxbaum, J.N., Ikeda, S., Merlini, G., Saraiva, M.J.M. and Westermark, P. (2016) Amyloid Fibril Proteins and Amyloidosis: Chemical Identification and Clinical Classification International Society of Amyloidosis 2016 Nomenclature Guidelines. Amyloid, 23, 209-213.

https://doi.org/10.1080/13506129.2016.1257986

[7] Invernizzi, G., Papaleo, E., Sabate, R. and Ventura, S. (2012) Protein Aggregation: Mechanisms and Functional Consequences. The International Journal of Biochemistry \& Cell Biology, 44, 1541-1554. https://doi.org/10.1016/j.biocel.2012.05.023

[8] Pastore, A. and Temussi, P. (2012) Protein Aggregation and Misfolding: Good or Evil? Journal of Physics: Condensed Matter, 24, 1-9. https://doi.org/10.1088/0953-8984/24/24/244101

[9] Stefani, M. (2004) Protein Misfolding and Aggregation: New Examples in Medicine and Biology of the Dark Side of the Protein World. Biochimica et Biophysica Acta, 1739, 5-25. https://doi.org/10.1016/j.bbadis.2004.08.004

[10] Clardy, J. and Walsh, C. (2004) Lessons from Natural Molecules. Nature, 432, 829837. https://doi.org/10.1038/nature03194

[11] Carocho, M. and Ferreira, I.C.F.R. (2013) A Review on Antioxidants, Pro-Oxidants and Related Controversy: Natural and Synthetic Compounds, Screening and Analysis Methodologies and Future Perspectives. Food and Chemical Toxicology, 51, 15 25. https://doi.org/10.1016/j.fct.2012.09.021

[12] Hawkes, C.A., Ng, V. and McLaurin, J.A. (2009) Small Molecule Inhibitors of a $\beta$-Aggregation and Neurotoxicity. Drug Development Research, 70, 111-124. https://doi.org/10.1002/ddr.20290

[13] Joynera, P.M. and Cichewicz, R.H. (2011) Bringing Natural Products into the FoldExploring the Therapeutic Lead Potential of Secondary Metabolites for the Treatment of Protein-Misfolding Related Neurodegenerative Diseases. Natural Product Reports, 28, 26-47.

[14] Mecocci, P. and Polidori, M.C. (2012) Antioxidant Clinical Trials in Mild Cognitive Impairment and Alzheimer's Disease. Biochimica et Biophysica Acta, 1822, 631- 
638. https://doi.org/10.1016/j.bbadis.2011.10.006

[15] Porat, Y., Abramowitz, A. and Gazit, E. (2006) Inhibition of Amyloid Fibril Formation by Polyphenols: Structural Similarity and Aromatic Interactions as a Common Inhibition Mechanism. Chemical Biology \& Drug Design, 67, 27-37. https://doi.org/10.1111/j.1747-0285.2005.00318.x

[16] Westermark, P., Wernstedt, C., Wilander, E., Hayden, D.W., O’Brien, T.D. and Johnson, K.H. (1987) Amyloid Fibrils in Human Insulinoma and Islets of Langerhans of the Diabetic Cat Are Derived from a Neuropeptide-Like Protein also Present in Normal Islet Cells. Proceedings of the National Academy of Sciences, 84, 3881-3885. https://doi.org/10.1073/pnas.84.11.3881

[17] Cooper, G.J.S., Leighton, B., Dimitriadis, G.D., Parry-Billings, M., Kowalchuk, J.M., Howland, K., Rothbard, J.B., et al. (1988) Amylin Found in Amyloid Deposits in Human Type 2 Diabetes Mellitus May Be a Hormone That Regulates Glycogen Metabolism in Skeletal Muscle. Proceedings of the National Academy of Sciences, 85, 7763-7767. https://doi.org/10.1073/pnas.85.20.7763

[18] Westermark, P., Andersson, A. and Westermark, G.T. (2011) Islet Amyloid Polypeptide, Islet Amyloid, and Diabetes Mellitus. Physiological Reviews, 91, 795-826. https://doi.org/10.1152/physrev.00042.2009

[19] Aarabi, M.-H. and Mirhashemi, S.M. (2012) The Role of Two Natural Flavonoids on Human Amylin Aggregation. African Journal of Pharmacy and Pharmacology, 6, 2374-2379. https://doi.org/10.5897/AJPP12.616

[20] Meng, F., Abedini, A., Plesner, A., Verchere, C.B. and Raleigh, D.P. (2010) The Flavanol (-)-Epigallocatechin 3-Gallate Inhibits Amyloid Formation by Islet Amyloid Polypeptide, Disaggregates Amyloid Fibrils, and Protects Cultured Cells against IAPP-Induced Toxicity. Biochemistry, 49, 8127-8133. https://doi.org/10.1021/bi100939a

[21] Mirhashemi, S.M. and Aarabi, M.-H. (2012) Effect of Two Herbal Polyphenol Compounds on Human Amylin Amyloid Formation and Destabilization. Journal of Medicinal Plants Research, 6, 3207-3212.

[22] Mirhashemi, S.M. and Aarabi, M.-H. (2012) To Evaluate Likely Antiamyloidogenic Property of Ferulic Acid and Baicalein against Human Islet Amyloid Polypeptide Aggregation, in Vitro Study. African Journal of Pharmacy and Pharmacology, 6, 671-676.

[23] Sharoyan, S., Antonyan, A., Mardanyan, S., Harutyunyan, H., Movsisyan, N., Hovnanyan, N. and Hovnanyan, K. (2013) Interaction of Dipeptidyl Peptidase IV with Amyloid Peptides. Neurochemistry International, 62, 1048-1054. https://doi.org/10.1016/j.neuint.2013.03.017

[24] Sharoyan, S.G., Antonyan, A.A., Harutyunyan, H.A. and Mardanyan, S.S. (2015) Inhibition of Amylin Fibril Formation and Protection of Islet $\beta$-Cells by Medicinal Plants. International Journal of Pharmacognosy, 2, 234-241.

[25] Sharoyan, S.G., Antonyan, A.A., Harutyunyan, H.A. and Mardanyan, S.S. (2015) Medicinal Plants Support the Amylin-Suppressed Viability of Islet $\beta$-Cells. International Journal of Pharmacognosy, 2, 448-453.

[26] Antonyan, A., Sharoyan, S., Harutyunyan, H., Movsisyan, N., Sargisova, Y.G., Stepanyan, H. and Mardanyan, S. (2014) Cytotoxicity of Some Edible Plants toward Ehrlich Ascites Carcinoma Cells. Research Journal of Medicinal Plants, 8, 20-31. https://doi.org/10.3923/rjmp.2014.20.31

[27] LeVine, H. (1993) Thioflavine T Interaction with Synthetic Alzheimer's Disease Beta-Amyloid Peptides: Detection of Amyloid Aggregation in Solution. Protein Science, 2, 404-410. https://doi.org/10.1002/pro.5560020312 
[28] Milton, G.N. and Harris, J.R. (2010) Human Islet Amyloid Polypeptide Fibril Binding to Catalase. The Scientific World Journal, 10, 879-893.

https://doi.org/10.1100/tsw.2010.73

Submit or recommend next manuscript to OALib Journal and we will provide best service for you:

- Publication frequency: Monthly

- 9 subject areas of science, technology and medicine

- Fair and rigorous peer-review system

- Fast publication process

- Article promotion in various social networking sites (LinkedIn, Facebook, Twitter, etc.)

- Maximum dissemination of your research work

Submit Your Paper Online: Click Here to Submit

Or Contact service@oalib.com 